\title{
CONOCIMIENTOS DEL PROFESORADO EN FORMACIÓN INICIAL SOBRE LA GUERRA CIVIL Y SU TRATAMIENTO EN LAS AULAS*
}

\author{
Knowledge about the Civil War and its Use in the \\ Classroom among Trainee Teachers
}

Ursula Luna

Universidad del País Vasco UPV/EHU. España ursula.luna@ehu.eus | https://orcid.org/0000-0003-1742-6035

Janire Castrillo

Universidad del País Vasco UPV/EHU. España janire.castrillo@ehu.eus | https://orcid.org/0000-0002-8128-9090

Iratxe Gillate

Universidad del País Vasco UPV/EHU. España iratxe.gillate@ehu.eus | https://orcid.org/0000-0001-6449-1804

Alex Ibañez-Etxeberria

Universidad del País Vasco UPV/EHU. España alex.ibanez@ehu.eus | https://orcid.org/0000-0001-9378-9714

Fecha de recepción: 02/08/2021

Fecha de aceptación: 25/11/2021

Acceso anticipado: 04/03/2022

Resumen: Este trabajo tiene como objetivo analizar los conocimientos que tiene el profesorado en formación de la Universidad del País Vasco sobre la guerra civil, y su posible uso en la etapa de primaria para el trabajo de temas y actitudes concretos. La metodología ha estado basada en un cuestionario de cuatro ítems, dirigido a identificar los personajes y acontecimientos que los y las futuros

* Grupos de investigación GIPyPAC (IT1193-19, PPG 17/68) y Sociedad Poder y Cultura (XIV-XVIII) (IT896-16) de la Universidad del País Vasco UPV/EHU. 
docentes conocen sobre la guerra, y a las temáticas y actitudes que piensan que podrían trabajarse en las aulas. Han participado 312 alumnos, cuyas respuestas han sido agrupadas en distintas categorías y a la postre cuantificadas. Los resultados indican que el alumnado reproduce los conocimientos adquiridos durante su etapa educativa anterior, esbozando un discurso basado en el desarrollo lineal de sucesos y acontecimientos bélicos, del que son protagonistas sobre todo personajes de índole política y militar. En conclusión, cabe hablar de la ausencia del tratamiento de la guerra civil desde una perspectiva crítica, y a partir de la memoria de colectivos silenciados u olvidados, lo que supone que el alumnado desconoce los posibles usos que pueden darse a un tema conflictivo como este en el aula y su potencialidad para trabajar la competencia cívica y ciudadana, la reflexión y la perspectiva crítica de la historia.

Palabras clave: Formación docente; Guerra civil; Educación Primaria; Competencia ciudadana.

Abstract: The aim of this study is to analyse the knowledge that trainee teachers at the University of the Basque Country have about characters and events of the civil war, and their possible use in Elementary Education to work on specific topics and attitudes. The study was carried out with 312 students, based on a questionnaire of four items. A high lack of knowledge has been found. On the one hand, the participants reproduce the knowledge acquired during their previous educational stage, in which the teaching of history was based on a straightforward narration of wartime happenings, with political and military figures as the main characters. The absence of a treatment of the civil war from a critical perspective, which integrates the memory of silenced or forgotten groups, means that students are not aware of the possible uses of a conflictive topic such as the civil war in the classroom. As a result, they are unaware of its potential for working on civic and citizenship skills, reflection, and a critical perspective on history. It is therefore advisable to include historical memory in compulsory education, as well as in the initial teacher training, in order to facilitate a change of perspective in the teaching of the civil war and its consequences in the present.

Keywords: Teacher training; Civil war; Elementary School; Civic competence.

Sumario: 1. Introducción; 2. Enseñar y aprender la guerra civil; 3. Método; 3.1. Participantes; 3.2. Instrumento de recogida y tratamiento de datos; 4. Resultados; 5 . Discusión; 6. Conclusiones; 7. Referencias bibliográficas.

\section{INTRODUCCIÓN}

La memoria sobre determinados hechos del pasado constituye el patrimonio compuesto por el conjunto de las vivencias de aquellos colectivos que las sociedades que los han acogido han considerado dignos de ser recordados. No es hasta estas últimas décadas cuando han comenzado a patrimonializarse las memorias de los vencidos en las guerras y otras minorías, que hasta entonces habían sido relegadas a un plano secundario, e incluso olvidadas u ocultadas (Acosta y Quintero, 
2008). Esas memorias emergentes, han comenzado a erigirse como un instrumento de determinados colectivos para ofrecer otras visiones de su identidad y del pasado, que trascienden los «relatos oficiales» (Llorente et al., 2016).

En este trabajo, partimos de la premisa de que la enseñanza aprendizaje de los temas socialmente conflictivos o candentes, además de ser válidos para reparar a las víctimas y su memoria, presentan un notable potencial para el desarrollo de la competencia ciudadana. Por ello, su presencia es conveniente en la enseñanza obligatoria y, en consecuencia, el tratamiento de temas conflictivos debe trabajarse también en los grados de formación de futuros docentes.Partiendo de esta base, este trabajo tiene como objetivo principal identificar los conocimientos de los que dispone el alumnado del Grado de Educación Primaria de la Universidad del País Vasco UPV/EHU sobre la guerra civil española, e indagar en las representaciones que posee acerca de su potencial didáctico. Sobre este, planteamos los siguientes objetivos específicos:Detectar los personajes y acontecimientos que el futuro profesorado relaciona de manera prioritaria con el devenir de la guerra civil.Examinar las temáticas de dicho ámbito que consideran adecuadas para llevar al aula y las actitudes que piensan que pueden trabajarse con ellas.

\section{ENSEÑAR Y APRENDER LA GUERRA CIVIL}

Los estudios sobre la memoria - y los distintos tipos de memoria - han sido elementos clave en la conceptualización de la historia más reciente y la percepción del pasado en diversos países (Tint, 2010). Desde el periodo de entreguerras, Halbwachs (1995) planteó la idea de memoria colectiva y Benjamín (1938, citado por Cuesta, 2014) destacó la necesidad de reconciliar la historia y la memoria en pos de la recuperación de la historia de los reprimidos. Tras la finalización de la Segunda Guerra Mundial, Alemania se presentó como eje principal en las investigaciones en torno al Holocausto y su memoria, en los que se tuvo que dar respuesta a posiciones muy distintas frente a los sucesos acontecidos y sus consecuencias (Figlio, 2017). Este tratamiento de las memorias como nuevas miradas a lo sucedido, y su influencia en la reconfiguración de la historia de los países afectados por distintos conflictos, generó procesos identitarios muy diferentes a nivel internacional, destacándose las acciones desarrolladas a partir de la década de los 80 (Olick y Robbins, 1998), en las que figuras como Yerushalmi o Pierre Nora destacaron por sus propuestas en torno a la concepción de memoria (González y Pagès, 2014). La llamada historia oficial tuvo que reedificarse a partir de la memoria colectiva, ofreciendo un punto de vista crítico sobre lo sucedido y perfilando nuevos espacios de reflexión común, convirtiéndose nuestro presente en "el tiempo de la memoria» (Aróstegui, 2004). Desde el conflicto entre Palestina e Israel (Nets-Zehngut, 2013), hasta el apartheid en Sudáfrica (Cunningham, 1999), o la represión política en Sudamérica 
(Jelin y Lorenz, 2004), son muchos los países en los que se ha planteado la necesidad de volver a revisar la historia del pasado, presente y futuro de la ciudadanía implicada en dichos conflictos.

En el contexto español, fueron las asociaciones para la recuperación de la memoria histórica, relacionada con la guerra civil y la transición, quienes comenzaron el proceso de reconocimiento de la represión sufrida por el bando perdedor (Gálvez, 2006; Gutiérrez, 2007). Ciertamente, no fue hasta el año 2007 cuando, con la promulgación de la llamada Ley de Memoria Histórica (Ley Orgánica 52/2007), el Estado español comenzó a dar pasos para la revisión de la represión perpetrada y sufrida.

Desde entonces, de manera progresiva, se han ido desarrollado acciones reparativas en pos de la verdad y la reconciliación, entre los que destaca el trabajo desarrollado en torno a lugares de memoria y museos (Arrieta Urtizberea, 2016), así como las acciones de educación patrimonial en espacios patrimonializados que han sido clave para la valoración y difusión de estos patrimonios (Hernández-Cardona y Rojo, 2012), como en el caso de la Batalla del Ebro (Roigé, 2016) o el Cinturón de Hierro de Bizkaia (Herrero y Ayán, 2016). Otro de los grandes trabajos que se está realizando en distintas partes de España ha sido el de la recuperación de testimonios de civiles, que ofrecen una visión alternativa a lo que supuso la guerra. Entre ellos, y dentro del ámbito final de este estudio, son destacables en el País Vasco el Proyecto Ahotsak ${ }^{1}$, la actividad del Instituto Gogora ${ }^{2}$ del Gobierno Vasco o la línea de trabajo desarrollada por la Sociedad de Estudios Aranzadi en torno a la memoria histórica ${ }^{3}$.

Con todo, si bien se ha desenrocado relativamente la memoria pública heredada del franquismo, las interpretaciones alternativas sobre la guerra y la dictadura no se han asumido aún con la debida contundencia en España ${ }^{4}$. Especialmente, si se comparan las políticas institucionales sobre derechos humanos implementadas en el país, con las de distintos países latinoamericanos que han pasado por procesos traumáticos similares (Izquierdo, 2018). En muchos casos, la mitificación de sucesos o la simplificación de lo sucedido han sido consecuencia del escaso trabajo realizado en torno a la historia reciente.

Abordar la memoria en las aulas es una cuestión de compromiso democrático, puesto que sirve para contar las "otras historias» que han sido ignoradas hasta

\footnotetext{
${ }^{1}$ Ahotsak.com.com - Archivo Oral Vasco. https://ahotsak.eus/spanish/

${ }^{2}$ Gogora. Instituto de la Memoria, la Convivencia y los Derechos Humanos. https://www. gogora.euskadi.eus/aa82-home/es/

3 Sociedad de ciencias Aranzadi. Memoria Histórica. https://www.aranzadi.eus/ antropologia-fisica/memoria-historica

${ }^{4}$ A fecha de hoy, nos encontramos en un proceso de involución del reconocimiento por una parte de la sociedad del golpe de Estado de 1936 como tal.
} 
tiempos recientes y hacer una labor de reparación respecto a las víctimas de distinta tipología (Delgado-Algarra, 2019), además de promoverse el análisis de los intereses políticos e ideológicos que llevan implícitos (Delgado-Algarra y Estepa, 2014). Trabajar los temas conflictivos o candentes pueden servir para educar históricamente en una ciudadanía no violenta, crítica, democrática (López-Facal y Santidrián, 2011), comprometida y competente con el pasado (Domínguez-Almansa y López-Facal, 2017), que sea capaz de tomar decisiones en una sociedad como la nuestra (Fernández Muñoz et al., 2018). Además, incluir la perspectiva de la «historia con memoria» que propone Cuesta (2014), constituye «un instrumento de conocimiento de la injusticia pasada proyectada sobre el presente y que se puede evitar en el futuro" (Domínguez-Almansa y López-Facal, 2016, p. 84). Del mismo modo, es necesario poder establecer vínculos emocionales con las víctimas de la barbarie en cuestión, contribuyendo a no olvidar las atrocidades cometidas en guerras y otros contextos de violencia (Estepa y Martín, 2018) y trabajando la empatía, elemento clave en el pensamiento histórico (Molina y Salmerón, 2020).

En el caso de la guerra civil española, hace años ya que se ha constatado la importancia de incluir el tema en el aula (Valls, 2007). Sin embargo, en la enseñanza obligatoria se aborda una "memoria mutilada», que perfila la guerra civil como un fenómeno de cariz bélico y político (Morgade, 2017), en el que el relato usual consiste en ofrecer una explicación de las fases de la guerra y las diferentes batallas acaecidas en su transcurso (Díez, 2013). Entre el contenido impartido de modo descontextualizado y estructurado en base al desarrollo cronológico y lineal de la guerra (Arias et al., 2019), se perpetúa la selección de hitos como símbolos de la guerra, como es el caso del bombardeo de Gernika (Roigé, 2016) o la Batalla del Ebro (Hernández-Cardona y Rojo, 2012). No se ahonda en temas de carácter más controvertido (Díez, 2013), ni se presenta como un fenómeno la represión de determinadas facciones de la sociedad, evitando la reflexión sobre los efectos del pasado en nuestro presente (Morgade, 2017).

A esto debemos sumarle la escasa presencia de temas sociales y culturales, así como la falta de inclusión del punto de vista de colectivos como las mujeres o los niños (Anguita Ortega, 2018). En efecto, en España, no se problematiza el recuerdo de su pasado reciente. Es corriente focalizar en una «república catastrófica», origen de una guerra fratricida y causante de una dictadura que restableció el orden social y modernizó la economía, y a cuyas víctimas cuesta aún reconocer como tales en distintos programas educativos (Izquierdo, 2018). Por ello, como señala Díez (2013), es necesario «replantear la historia desde la perspectiva de los perdedores, de los grupos oprimidos, de los represaliados, de los olvidados» (p. 405).

Las investigaciones realizadas sobre la presencia de la memoria en los libros de texto españoles refuerzan esta idea, ya que han denotado también amplias carencias, siendo infrecuente encontrar referencias a las personas que aún siguen desaparecidas, al hallazgo de fosas comunes y a la existencia de asociaciones para la recu- 
peración de la memoria (Sánchez-Lafuente, 2008). Se presentan los acontecimientos como "hechos cerrados», en los que no existe un espacio para la reflexión y el debate (Bel y Colomer, 2017), lo que supone la aceptación del alumnado como «receptor acrítico de conocimientos acabados» (Maestro, 2002, p. 33). Ese enfoque restrictivo es uno de los motivos que ha llevado a plantear el uso de recursos didácticos alternativos, como el uso de fuentes históricas (Payà, 2013); recursos literarios y cinematográficos (Ibars y López, 2006; López Serrano, 2019); o también tecnológicos, como redes sociales (Eiroa, 2020) o apps (Castrillo et al., 2021; Gillate et al., 2020).

Ciertamente, las investigaciones que recientemente han indagado en los conocimientos que posee el alumnado español con relación a la guerra civil al terminar la etapa de educación secundaria evidencian amplias lagunas y preocupantes errores. Ello pone de manifiesto una escasa alfabetización política del alumnado y la falta de fomento de la reflexión en torno a las repercusiones de ese periodo histórico en la sociedad actual (Arias et al., 2019). También debemos destacar el enfoque expositivo y memorístico en el que se sigue basando la enseñanza de la historia (Ibagón y Miralles, 2019); una metodología acentuada por la formación de los docentes, el planteamiento del currículum (Duarte Piña, 2018) y, en parte, por el diseño de los exámenes de acceso a la universidad (Saíz y Fuster, 2014). Así, como ya destacan en su trabajo Fernández Muñoz et al. (2018), el alumnado se debate entre saber historia, formarse como ciudadanos o aprobar la selectividad. Una enseñanza de la historia que, por contra, debería plantearse desde un punto de vista crítico, como una "historia problematizada» (Sánchez-Agustí et al., 2019, p. 251).

Tampoco debemos olvidar que los conocimientos adquiridos sobre cualquier temática no solo tienen su origen en el ámbito académico. Los medios de comunicación y las redes sociales tienen una gran influencia en la creación del imaginario colectivo y son generadores de opinión, estableciendo así lo que Martínez Rodríguez (2014) llama «memoria mediática». Existen numerosos ejemplos de películas basadas en hechos de la guerra civil, series sobre personajes como Clara Campoamor y biopics basados en las vidas de Juan Carlos I o Alfonso Suárez. También la música ha sido una fuente de información y reflexión en las últimas décadas, en las que se han conmemorado a las víctimas de la guerra o se han criticado procesos políticos y bélicos del pasado unidos a la guerra, la dictadura y la transición, siendo en muchas ocasiones hechos conflictivos de gran repercusión en la sociedad.

Por todo ello, varios autores han subrayado la importancia de que los futuros docentes reciban una formación (Pagès, 2019) y aprendan a integrar los temas conflictivos y su valor patrimonial en las aulas (Castrillo et al., 2021; Delgado-Algarra y Estepa, 2016; Domínguez-Almansa y López-Facal, 2016; 2017; López-Facal y Santidrián, 2011). Sin embargo, diversas investigaciones realizadas con profesorado en formación han señalado que el alumnado no se siente suficientemente capacitado para incluir contenidos de competencia ciudadana en sus propuestas didácticas (Molina et al., 2013) o para incluir temas de la historia pasada (Sonlleva y Sanz, 
2019), debido a las carencias en su formación universitaria. Otros también han mostrado el desconocimiento sobre el uso que puede tener el tratar temas conflictivos como la guerra civil en el aula (Domínguez-Almanza y López-Facal, 2017)

Ante esta situación, son varios los trabajos en los que se han desarrollado propuestas educativas para el tratamiento de la guerra civil en distintas etapas educativas. Ejemplo de ello son la satisfacción y la percepción del aprendizaje mostradas por estudiantes del Grado de Educación Primaria de la Universidad de Barcelona, tras haber realizado una visita al entorno de la Batalla del Ebro (Rojo et al., 2014). Otra propuesta desarrollada en la Universidad de Huelva en que se trató el Valle de los Caídos en el Máster de formación del profesorado resultó óptima para suscitar el debate en el aula (Estepa y Delgado-Algarra, 2021). También el trabajo realizado tanto con alumnado del Grado de Educación Primaria de la Universidad de Santiago de Compostela, como su posterior implementación en un contexto real con estudiantes de primaria, mostró la valoración favorable sobre el uso del patrimonio en conflicto como elemento para desarrollar el tratamiento de las emociones y la reflexión crítica del pasado. Sin embargo, destacaron la dificultad de introducir el tema en el aula por la complejidad de su contenido y por las situaciones de tensión que puedan generar, sobre todo, en las familias del alumnado (Domínguez-Almansa y López-Facal, 2017).

\section{MÉTODO}

En esta investigación, aplicamos un modelo de investigación cualitativa, basada en una codificación y categorización de los datos (Flick, 2015), cuyas frecuencias cuantificamos presentando los resultados con el método estadístico descriptivo.

\subsection{Participantes}

La muestra se conforma de 312 participantes del Grado de Educación Primaria de la Universidad del País Vasco UPV/EHU. 151 (48,4 \%) pertenecen al campus de Bizkaia, 108 (34,6\%) al de Gipuzkoa y 53 (17\%) al de Álava. Se trata de una muestra intencional en la que los participantes están cursando el tercer curso de dicho grado, matriculados en la asignatura Didáctica de las Ciencias Sociales II y realizan los estudios de manera presencial.

\subsection{Instrumento de recogida y tratamiento de datos}

Para la recogida de datos se ha creado un cuestionario auto-aplicado que consta de 4 ítems de respuesta abierta sobre el conocimiento acerca de la guerra civil y su tratamiento en el aula (Tabla 1 ). 
TABLA 1. Ítems del cuestionario sobre la guerra civil

N.음

Ítem

\begin{tabular}{ll}
\hline $\mathbf{1}$ & Escribe tres personajes de la guerra civil española \\
$\mathbf{2}$ & Escribe tres acontecimientos de la guerra civil española \\
$\mathbf{3}$ & $\begin{array}{l}\text { Escribe tres conceptos (temas) que llevarías al aula para trabajar la guerra civil } \\
\text { española }\end{array}$ \\
$\mathbf{4}$ & $\begin{array}{l}\text { Escribe tres actitudes que pueden trabajarse al abordar en la escuela la guerra } \\
\text { civil española }\end{array}$ \\
\hline
\end{tabular}
Fuente: Autores.

La recogida de datos se ha realizado durante el curso 2020-2021, desde septiembre hasta mayo. Los datos del cuestionario se han recogido en una tabla de Excel creada a partir de las respuestas

Tras la obtención de las respuestas totales, se ha procedido a diseñar la ficha de codificación. Se han establecido las categorías específicas para cada ítem que engloban las respuestas ofrecidas por los participantes (Tabla 2). En el primer ítem, Personajes, se han establecido 13 categorías; en el segundo, Acontecimientos, 9; en el tercero, Temas para llevar al aula, 14; y en el cuarto, Actitudes para llevar al aula, 13.

TABLA 2. Categorías establecidas para las respuestas de cada ítem

ÍTEM

1. Personajes

1- Reyes | 2- Dictadores |3- Militares bando republicano | 4- Militares bando sublevado | 5- Políticos (izq.) | 6- Políticos (dcha.) | 7-Cargos policiales | 8-Personajes de la cultura | 9- Dictadores internacionales | 10- Personajes relacionados con sucesos vascos | 11- Sindicalistas, anarquistas | 12- Personajes civiles | 13- Fuera de contexto

2. Acontecimientos 1-Inicio de la guerra | 2-Acontecimientos bélicos | 3-Políticos

| 4- Culturales| 5- Relacionados con la violencia| 6- Sociales|

7- Económicos | 8-Temas generales| 9- Fuera de contexto

3. Temas para llevar al aula

1- Desarrollo de la guerra | 2- Acontecimientos concretos | 3- Política

| 4-Social | 5-Cultura-educación | 6- Economía| 7- Emociones/ sentimientos | 8- Muertes|asesinatos| 9- Contexto internacional | 10- Personajes | 11- Relación con la sociedad/historia actual | 12- Conceptos generales | 13- Relacionados con contenidos de CCSS | 14- Fuera de contexto

4. Actitudes para 1-Emociones/sentimientos | 2-Ciudadanía| 3-Empatía| 4- Reflexión| trabajar en el aula 5-Actitud crítica| 6-Concienciación/sensibilización | 7-Interés

| 8-Comprensión del presente | 9- Posicionamiento ideológico|

10- Lucha | 11- Actitudes positivas | 12- No son actitudes, son

actividades | 13- No son actitudes, son conceptos 
En cuanto a las reglas de análisis y los códigos de clasificación (Cáceres, 2003), hemos establecido como pauta recoger solo las tres primeras respuestas ofrecidas por cada participante en cada ítem. De manera que, si un participante ha ofrecido más de tres respuestas, solo se han seleccionado las tres primeras. En el caso de que se hayan ofrecido menos de tres respuestas, las ausencias se han incluido en la categoría NS/NC.

Además, cuando en las respuestas se ha repetido la misma idea, se ha recogido como una sola respuesta (por ejemplo, si se ha respondido "dos bandos» y «dos grupos»). En la categoría de acontecimientos solo se han recogido aquellas respuestas que responden a un suceso concreto, y las que muestran solo el nombre de un lugar se han categorizado como NS/NC (por ejemplo, cuando el alumnado ha respondido "Covadonga» o "Madrid»), por el hecho de que no están indicando cuál es el acontecimiento concreto que recuerdan.

Se han agrupado las respuestas que no responden directamente a la pregunta del cuestionario en categorías genéricas. Por ejemplo, en los ítems 1,2 y 3 , encontramos menciones de personajes, acontecimientos y temas al margen de lo que se está preguntando, que hemos incluido en la categoría «Fuera de contexto». En el ítem 4 algunos participantes han confundido conceptos y actividades con las actitudes que pueden trabajarse en el aula. En este caso, se han creado sendas categorías: una llamada "No son actitudes, son actividades», y otra "No son actitudes, son conceptos». En este último ítem, también hemos creado una categoría llamada «Emociones/sentimientos» que, aunque no responde de manera directa a una actitud, hemos considerado como tal, ya que la guerra y su memoria pueden trabajarse también desde esa perspectiva.

Esto ha permitido realizar un análisis de los datos de cada ítem en dos niveles. Primero, se han cuantificado las respuestas totales de cada ítem, identificando los términos más nombrados y de frecuencia mayor de diez. En segundo lugar, se clasifican las respuestas de cada ítem en las categorías arriba establecidas y se cuantifican sus frecuencias, identificando las que tienen mayor o menor presencia.

Para la realización de estos análisis de frecuencias se ha utilizado el programa IBM SPSS Statistics 26 y el método estadístico descriptivo.

\section{RESULTADOS}

En el ítem 1, donde se pregunta al alumnado sobre los personajes de la guerra civil que conocen (Gráfico 1), encontramos en primer lugar, como personaje más nombrado, a Francisco Franco, con una frecuencia de 256 (27.4\%). En segundo lugar, con una frecuencia de 229 (24.5\%), no se ha contestado a la pregunta o se ha respondido que se desconoce. Con una notable diferencia en cuanto al número de respuestas, se menciona a Emilio Mola ( $n=85 ; 9.8 \%$ ), Manuel Azaña ( $n=84$; 
GRÁFICO 1. Resultados principales del ítem 1 «Escribe tres personajes de la guerra civil española»

\section{Resultados principales del ítem 1}

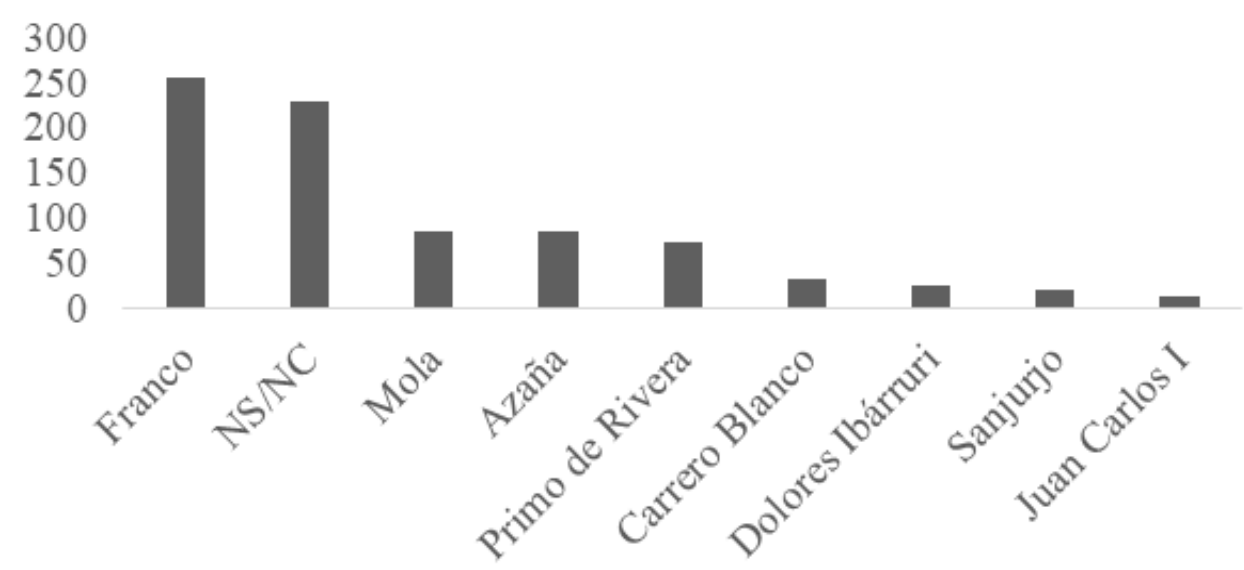

Fuente: Autores.

$9 \%$ ) y Primo de Rivera ( $n=72 ; 7.7 \%$ ). Por último, podemos destacar la presencia de Carrero Blanco, con 33 respuestas (3,5\%), Dolores Ibárruri con 25 (2.7\%), General Sanjurjo con 19 (2 \%) y Juan Carlos I con 12 (1.3\%).

Los tipos de personajes más nombrados (Gráfico 2), han sido los relativos a la categoría dictadores, que ha obtenido un $35 \%$ de las respuestas ( $n=328$ ). El segundo puesto lo ocupa NS/NC con 229 respuestas (24.5\%). En tercer lugar, encontramos a políticos de ideología izquierdista, mencionados 151 veces (16.1\%). Los militares relacionados con el golpe de Estado del 36 ocupan el cuarto puesto ( $n=109 ; 11.6 \%$ ), seguidos de los políticos de partidos de derecha ( $n=40 ; 4.3 \%$ ). Después, encontramos a reyes ( $n=21 ; 2 \%)$, entre los que figuran Juan Carlos I, Alfonso XIII o Felipe VI, y a personajes relacionados con la cultura ( $n=21 ; 2 \%$ ) como Lorca, Unamuno o Machado. Los personajes fuera de contexto, como Cánovas del Castillo o Carlomagno, han sido mencionados en 8 ocasiones (0.9\%), con el mismo número de menciones ( $n=8 ; 0.9 \%$ ) encontramos a personajes del contexto vasco, como José Antonio Aguirre o Alejandro Goicoechea, y a cargos policiales ( $\mathrm{n}=8$; $0.9 \%)$ como Melitón Manzanas. Por último, se nombra a personajes internacionales, como Hitler o Mussolini, en 5 respuestas (0.5\%); a militares de ideología izquierdista en $4(0.4 \%)$, a sindicalistas y milicianas en otras $4(0.4 \%)$; y a civiles como Agapita Iturralde en otras 4 ocasiones (0.4\%).

En el ítem 2, donde se pregunta al alumnado sobre los acontecimientos que conocen de la guerra civil (Gráfico 3), la respuesta mayoritaria corresponde a NS/NC 
GRÁFICO 2. Tipos de personajes más nombrados en las respuestas al ítem 1 «Escribe tres personajes de la guerra civil española»

Frecuencias de tipos de personajes

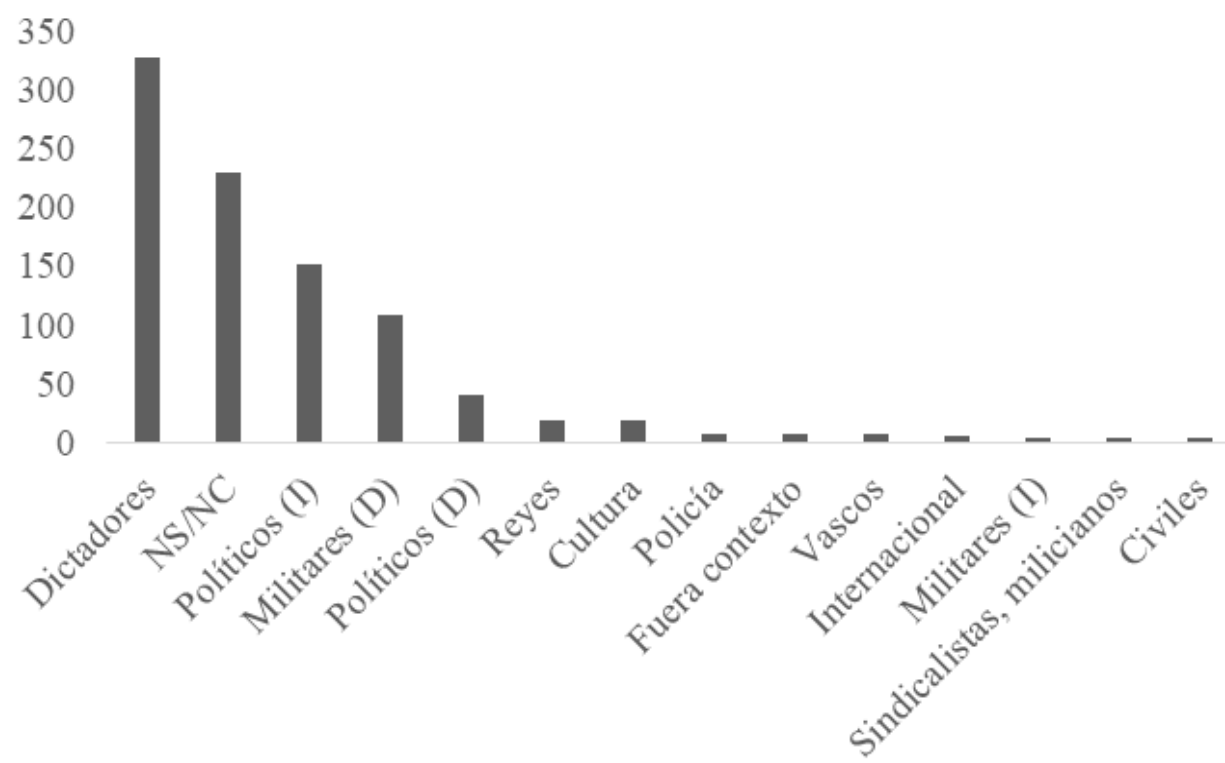

Fuente: Autores.

( $n=261 ; 27.9 \%$ ). Después, los más citados son el bombardeo de Gernika ( $n=159$; $17 \%$ ) y el golpe de Estado ( $n=141 ; 15.1 \%$ ). El asesinato de Lorca obtiene un total de 63 menciones (6.7\%), seguido de la rotura del Cinturón de Hierro o la toma de Bizkaia ( $n=30 ; 3.2 \%)$, la Batalla de Ebro $(n=27 ; 2.9 \%)$, el franquismo $(n=23$; $2.5 \%)$, el asesinato de Primo de Rivera $(n=22 ; 2.6 \%)$, la Batalla del Jarama $(n=17$; $1.8 \%$ ) y la guerra como acontecimiento en sí mismo $(n=17 ; 1,8 \%)$. Por último, se mencionan la toma de Madrid ( $n=11 ; 1.2 \%$ ), los fusilamientos y asesinatos de manera genérica $(n=11 ; 1.2 \%)$ y la II República $(n=10 ; 1.1 \%)$.

Analizados los acontecimientos a partir de las categorías establecidas (Gráfico 4), podemos observar que los sucesos bélicos ocupan el primer puesto $(n=268$; $28.6 \%$ ), seguidos de 261 respuestas ( $27.9 \%$ ) de la categoría de NS/NC. Ocupan el tercer lugar, las respuestas agrupadas en la categoría Inicio de la guerra, con 142 (15.2 \%) casos, tras lo cual encontramos acontecimientos relacionados con la violencia $(n=104 ; 11.1 \%)$. Son menos numerosas las respuestas agrupadas en la categoría de acontecimientos relacionados con la política $(n=54 ; 5.8 \%)$ y aquellos categorizados como "generales» $(n=43 ; 4.6 \%)$, como pueden ser catástrofe, gente en guerra o lucha entre bandos. Después encontramos la categoría de temas sociales $(n=31 ; 3.3 \%)$, en el que se mencionan la censura, las huelgas o las migraciones, 
GRÁFICO 3. Resultados principales del ítem 2 «Escribe tres acontecimientos de la guerra civil española»

Resultados principales del ítem 2

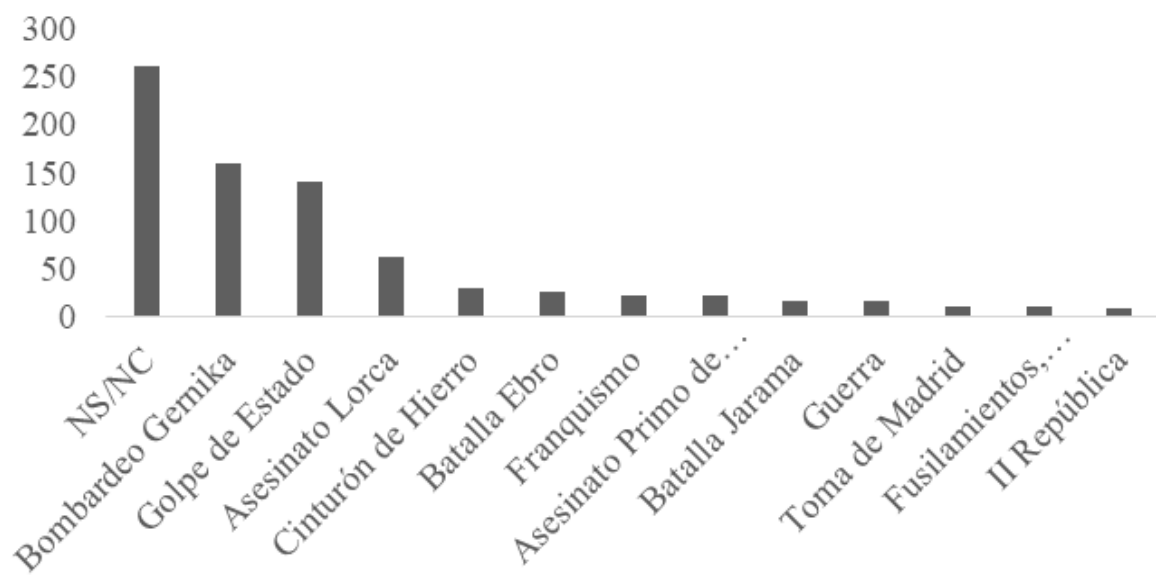

Fuente: Autores.

seguida de la categoría de acontecimientos que se encuentra fuera del contexto sobre el que se pregunta $(n=25 ; 2.7 \%)$, como las guerras carlistas o la Conferencia de Múnich. Los acontecimientos culturales $(n=6 ; 0.6 \%)$ y económicos $(n=2 ; 0.2 \%)$ ocupan los últimos puestos.

GRÁFICO 4. Tipos de acontecimientos más nombrados en las respuestas al I ítem 2 «Escribe tres acontecimientos de la guerra civil española»

Frecuencias de tipos de acontecimientos

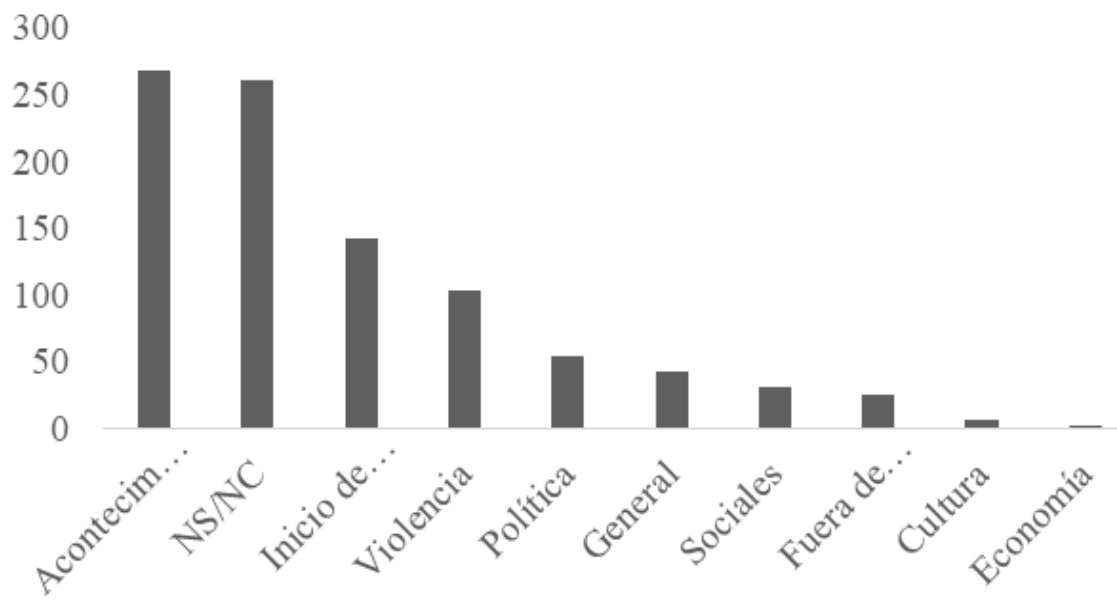

Fuente: Autores. 
En el ítem tres, donde se pregunta sobre tres conceptos o temas que podrían trabajarse en el aula (Gráfico 5), observamos que las respuestas están más diversificadas que en los anteriores ítems. En primer lugar, un $14.5 \%(n=136)$ del total de las respuestas han sido NS/NC. Tras ellas, la propuesta de trabajar las consecuencias de la guerra se menciona en 61 ocasiones $(6,5 \%)$, seguido de la dictadura $(n=56 ; 6 \%)$, las causas de la guerra $(n=54 ; 5.8 \%$ y y la República $(n=43 ; 4,6 \%)$. Después, se menciona el golpe de Estado ( $n=38 ; 4.1 \%)$, la guerra como concepto $(n=31 ; 3.3 \%)$, el bombardeo de Gernika ( $n=27 ; 2.9 \%$ ), el desarrollo de la guerra y su datación $(n=27$; $2.9 \%)$, los bandos ( $n=267 ; 2.8 \%)$, el franquismo $(n=25 ; 2.7 \%)$, el fascismo y nacismo $(n=24 ; 2,6 \%)$, y también las distintas ideologías $(n=23 ; 2.5 \%)$. Con frecuencias menores a 20, encontramos otros 9 temas, entre los que figuran el papel de las mujeres $(n=16 ; 1.7 \%)$, la represión $(n=13 ; 1.4 \%)$ o la pobreza $(n=12 ; 1.3 \%)$.

En la categorización de los temas para trabajar en el aula (Gráfico 6), advertimos, en primer lugar, la presencia de temas del ámbito político $(n=239 ; 25.5 \%)$ o relacionados con el desarrollo histórico de la guerra $(n=239 ; 25.5 \%)$. El segundo lugar lo ocupa la categoría NS/NC con 136 respuestas (14.5\%). Las temáticas sociales se proponen en 84 ocasiones ( $9 \%$ ), seguido de acontecimientos o hechos concretos ( $n=75 ; 8 \%$ ) y del ámbito económico ( $n=35 ; 3.7 \%)$. Tras ellos, las emociones o los sentimientos se presentan como posible tema a tratar en 21 respuestas ( $2.3 \%)$, la cultura en $17(1.8 \%)$, seguido de personajes $(n=15 ; 1.6 \%)$, y muertes y

GRÁFICO 5. Resultados principales del ítem 3 «Escribe tres conceptos (temas) que llevarías al aula para trabajar la guerra civil española»

Resultados principales del ítem 3

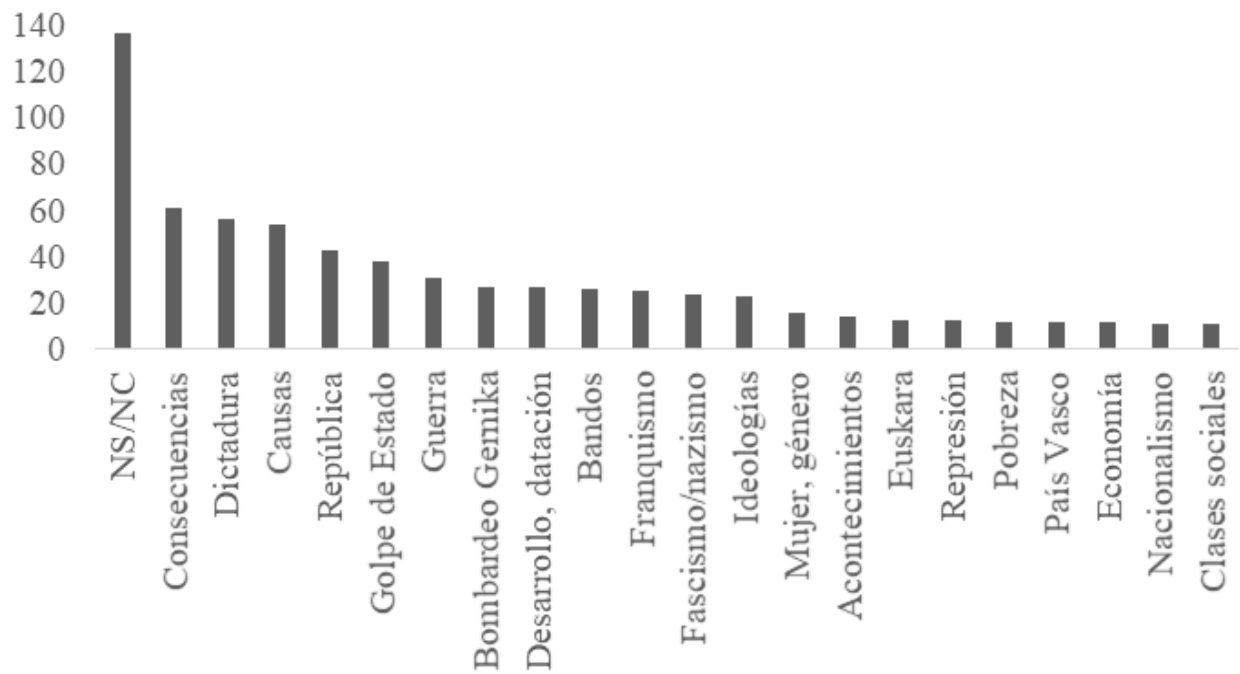

Fuente: Autores 
GRÁFICO 6. Tipos de temas más nombrados en las respuestas al ítem 3 «Escribe tres conceptos (temas) que llevarías al aula para trabajar la guerra civil española»

\section{Frecuencias de tipos de temas para trabajar en el aula}

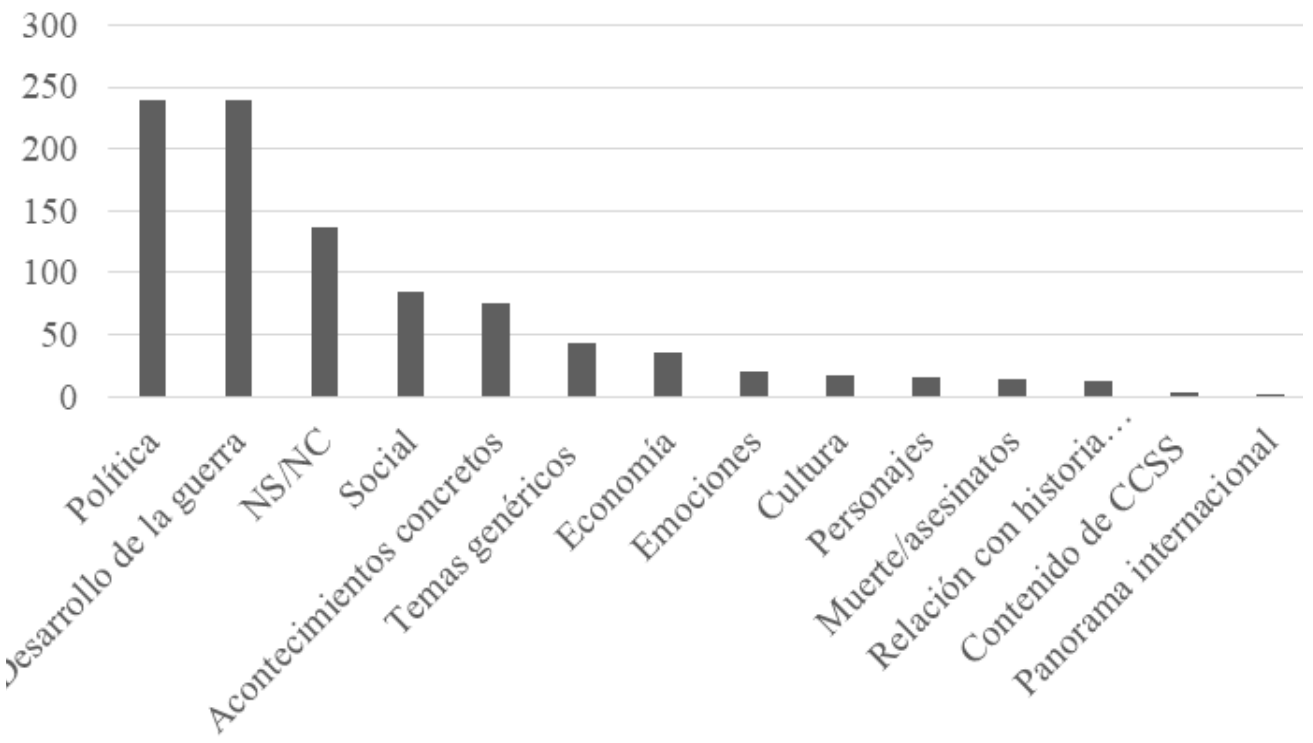

Fuente: Autores.

asesinatos ( $n=14 ; 1.5 \%)$. Después, se nombran los temas que relacionan la guerra con la sociedad o historia actual $(n=12 ; 1.4 \%)$, tras lo cual encontramos contenidos específicos de CC. SS. $(n=4 ; 0,4 \%)$ y temas que muestran el panorama internacional de la época $(n=2 ; 0.2 \%)$.

Por último, en el ítem 4, donde se plantea a los participantes qué tipo de actitudes podrían trabajarse en el aula (Gráfico 7), destaca la alta frecuencia de NS/NC $(n=261 ; 27.9 \%)$. La empatía se menciona en 85 ocasiones en total $(9,1 \%)$, seguido del respeto $(n=52 ; 5,6 \%)$, las respuestas que proponen conceptos y no actitudes ( $n=51 ; 5,4 \%)$, el interés por conocer la historia y/o el pasado $(n=50 ; 5,3 \%)$ y la actitud crítica ( $n=41 ; 4,4 \%$ ). Después, encontramos la actitud de desarrollar una opinión propia o posicionarse ideológicamente $(n=25 ; 2,7 \%)$, de conciencia o sensibilización ( $n=24 ; 2,6 \%)$, de interés o conocimiento $(n=22 ; 2,4 \%)$, de reflexión ( $n=19 ; 2 \%$ ) e igualdad ( $n=19 ; 2 \%$ ). Junto con estas últimas actitudes, observamos que se confunden las actividades con las actitudes en 19 casos (2\%). Por último, también podemos destacar la actitud activa y participativa $(n=17 ; 1,8 \%)$, de interés por conocer la influencia de la guerra en el presente $(n=16 ; 1,7 \%)$, la actitud tolerante $(n=15 ; 1,6 \%)$ y el posicionamiento antifascista y antifranquista $(n=13$; $1,4 \%)$. 
GRÁFICO 7. Resultados principales del ítem 4 «Escribe tres actitudes que pueden trabajarse al trabajar en la escuela la guerra civil española»

\section{Resultados principales del ítem 4}

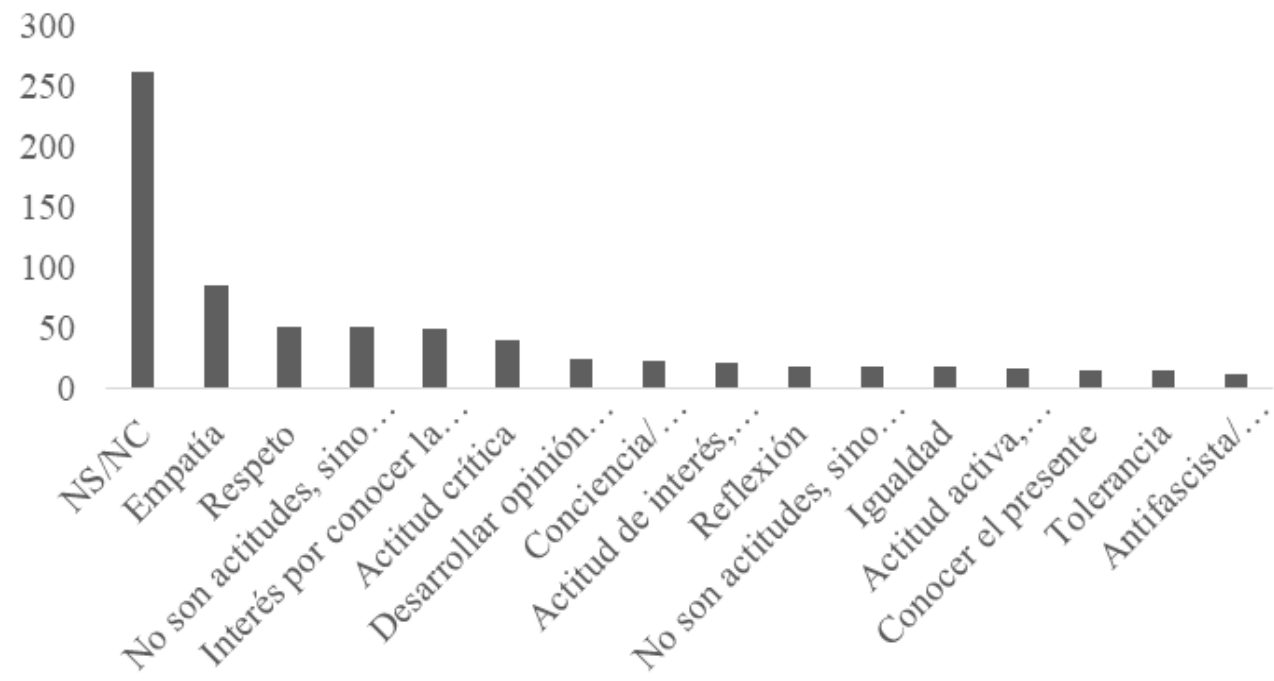

Fuente: Autores.

En cuanto a los tipos de actitudes más nombrados en el ítem 4 (Gráfico 8), la respuesta NS/NC ocupa el $27,9 \%(n=261)$ de las respuestas totales. En cuanto a los grupos temáticos de actitudes que se plantean trabajar, destacamos la actitud ciudadana $(n=173 ; 18.5 \%)$. En un tercer puesto se plantean actitudes relacionadas con el interés ( $n=87 ; 9.3 \%)$, seguido de la empatía $(n=85 ; 9.1 \%)$. Después, encontramos el grupo de emociones y/o sentimientos $(n=63 ; 6.7 \%)$, las respuestas que mencionan conceptos y no actitudes $(n=51 ; 5.4 \%)$, la actitud crítica $(n=41$; $4.4 \%)$, de posicionamiento ideológico $(n=40 ; 4.3 \%$ ) y actitudes positivas $(n=32$; $3.4 \%$ ). Tras ellas se encuentran las actitudes que proponen relacionar la guerra con la sociedad actual ( $n=27 ; 2.9 \%)$, la de concienciación y/o sensibilización ( $n=24$; $2.6 \%$ ), de reflexión ( $n=19 ; 2 \%$ ), las respuestas que proponen actividades, en vez de actitudes $(n=19 ; 2 \%), y$, por último, actitudes relacionadas con la lucha $(n=14$; $1.5 \%)$. 
GRÁFICO 8. Tipos de actitudes más nombradas en las respuestas al ítem 4 «Escribe tres que pueden trabajarse al trabajar en la escuela la guerra civil española»

Frecuencias de tipos de actitudes para trabajar en el aula

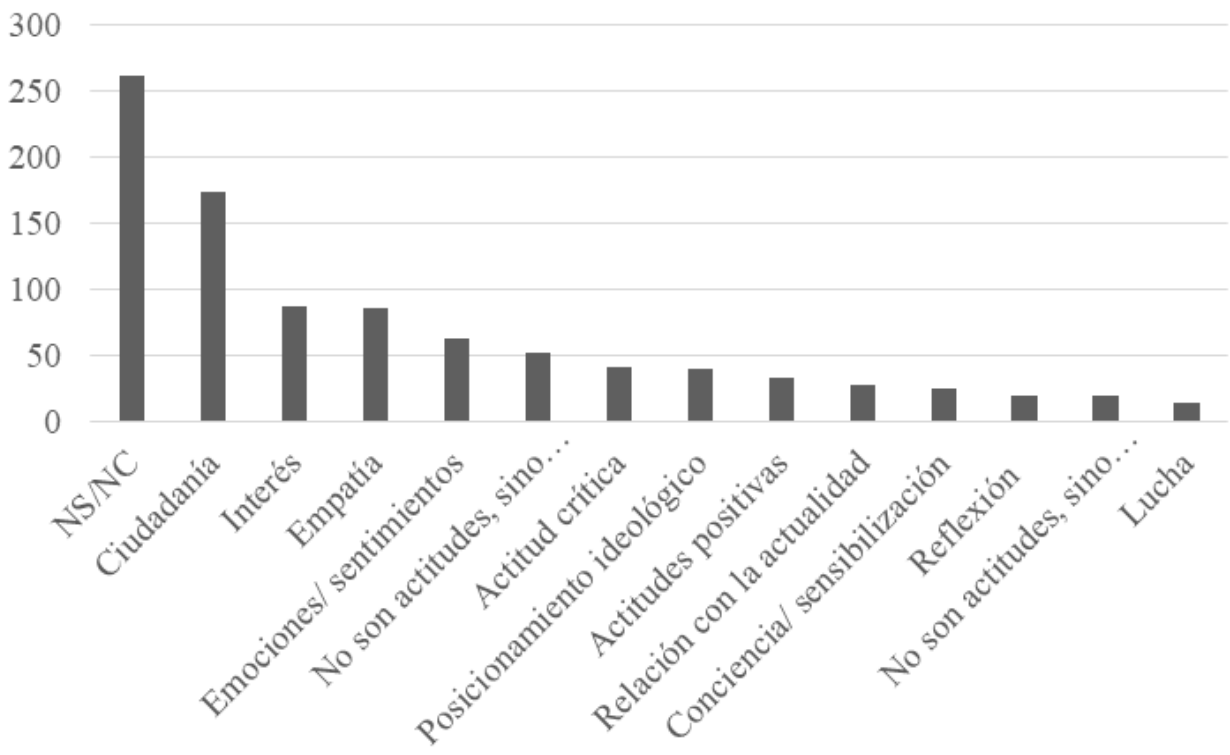

Fuente: Autores

\section{DISCUSIÓN}

Los datos obtenidos muestran una tendencia global que debe destacarse en primer lugar. Es llamativo que las respuestas NS/NC ocupan el primer puesto de frecuencias totales, exceptuando el ítem 1 en el que ocupa un segundo puesto, con una diferencia muy escasa en frecuencias respecto a la respuesta más nombrada. Esto demuestra que, tal y como destacan Arias et al. (2019), existe una falta de alfabetización enorme en la historia de la guerra civil en el alumnado que termina la secundaria y que es, en este caso, el futuro alumnado de los grados de educación.

Los resultados denotan la focalización de la enseñanza de la guerra civil en los hechos bélicos y políticos (Morgade, 2017). Muestra de ello es la alta frecuencia de menciones a dictadores, militares y políticos, sobre los que predomina la presencia inevitable de Francisco Franco. Los tipos de personajes más nombrados tras los dictadores son los políticos, especialmente los de izquierda, como Azaña, que aparece como uno de los más mencionados como parte del gobierno de la República, y los de derechas pierden protagonismo al ser los militares los que ganan peso. Entre 
estos últimos, militares como Mola o Sanjurjo son mencionados, unidos al inicio de la guerra con el golpe de Estado.

También la mención de sucesos bélicos o unidos al desarrollo de la guerra, como el golpe de Estado, refuerza la idea del contenido de la guerra civil que se sigue impartiendo en la enseñanza obligatoria, donde se narran hechos de manera lineal (Arias et al., 2019) y que están dirigidos, principalmente en segundo de bachillerato, a la memorización de acontecimientos descontextualizados que permitan aprobar el examen de acceso a la universidad (Fernández Muñoz et al., 2018). El acontecimiento más mencionado es el bombardeo de Gernika, conocido internacionalmente gracias a la obra de Picasso, por haberse convertido en uno de los símbolos principales en el relato de la guerra y, además, por el contexto en el que se ha desarrollado la investigación, puesto que los participantes pertenecen al País Vasco y el suceso pertenece a la memoria colectiva de la ciudadanía de este territorio (Herrán y Ayén, 2016). También se menciona la rotura del Cinturón de Hierro de Bizkaia, sobre el cual, durante la última década, se ha realizado una importante labor de patrimonialización, lo que muestra la importancia de estos procesos para el conocimiento de hechos históricos por parte de la ciudadanía (Arrieta Urtizberea, 2016). Otros acontecimientos como las batallas de Ebro y el Jarama, la toma de Madrid y otras ciudades o los distintos tipos de gobierno precedentes y posteriores a la guerra son mencionados en mayor número, aunque denotan la repetición de temáticas predominantes en los ítems 1 y 2.

Los temas propuestos para trabajar en el aula también coinciden con esta línea. Las menciones a trabajar las causas, consecuencias, desarrollo y datación de la guerra, la dictadura y la República, el golpe de Estado o ideologías políticas, como el fascismo y el nacismo, coinciden con el contenido de la guerra civil que se sigue impartiendo en la enseñanza obligatoria y que proponen lo sucedido como hechos cerrados (Bel y Colomer, 2017), impartidos desde un enfoque expositivo y aprendidos de manera memorística (Ibagón y Miralles, 2019; Saíz y Fuster, 2014). Del mismo modo, al no trabajarse la guerra civil en los grados de formación de profesorado (Domínguez-Almansa y López-Facal, 2017), los participantes siguen repitiendo los esquemas e ideas que les fueron transmitidos durante la secundaria y el bachillerato.

Además de las menciones, son destacables las ausencias en las respuestas de los participantes. Continuamos viendo que se desconocen mayoritariamente los personajes del bando de los vencidos o los pertenecientes a minorías, esas «otras historias» que han sido ignoradas (Delgado-Algarra, 2019). Como ejemplo, podemos observar que, aunque los asesinatos y fusilamientos se posicionan como unos de los acontecimientos más nombrados, y los actos violentos se encuentran en el cuarto lugar como tipo de hechos más mencionados, apenas se menciona a las víctimas y no se conocen los nombres de personajes que pertenezcan a estas minorías. Todo ello tiene relación con la ausencia de menciones en los libros de texto y 
currículum de enseñanza obligatoria de estas víctimas (Izquierdo, 2018), así como del trabajo que realizan las asociaciones de recuperación de la memoria (SánchezLafuente, 2009).

Pese a ello, entre las propuestas temáticas para trabajar en el aula, destacan la presencia de los temas sociales como la pobreza, el idioma o la represión, que también están unidos a lo político. Sin embargo, no han sido capaces de reconocer personajes unidos a estas temáticas, reforzando la necesidad de recuperar los testimonios de los olvidados (Acosta y Quintero, 2018). Lo mismo sucede con la presencia de la violencia, que sí es destacable tanto en los tipos de acontecimientos, como en las temáticas a incluir en el aula, aunque apenas se menciona a personas que sufrieron la violencia, en línea con el discurso oficial aceptado durante décadas que ha invisibilizado a las víctimas de la represión franquista.

Entre estos colectivos silenciados debemos destacar el papel de las mujeres, que ha sido sistemáticamente ignorado y eliminado del discurso histórico sobre la guerra civil (Anguita Ortega, 2018). Entre las pocas veces en las que se les cita en las respuestas, aparece en dos ocasiones Clara Campoamor, protagonista de una de las últimas series de televisión emitidas, o personajes civiles mencionados en algunas canciones de grupos de música conocidos, como Agapita Iturralde y Catalina Barrena. También se recoge una mención a Juana Francisca y otra a María Ginestá, aunque son, en todo caso, datos residuales. Como sabemos, el peso de la historia política recae en los hechos y sucesos narrados por hombres, donde son ellos quienes tienen el poder político o de mando y son, además, los que narran la historia. Como excepción, debemos destacar a Dolores Ibárruri, siendo un personaje que puede resultar conocido para ciertos participantes por su origen vizcaíno y, por ser una de las figuras que se ha destacado en los últimos años desde los estudios feministas (Gillate et al., 2016).

Desde la perspectiva cultural, es llamativa la presencia de personajes como Lorca o Unamuno. En el caso del primero, aparece su asesinato como uno de los tres primeros acontecimientos más mencionados. Este hecho es muestra del imaginario colectivo que existe en la actualidad sobre la represión del bando sublevado frente a personajes de la cultura. También se ha recogido entre las respuestas como acontecimiento el discurso de Unamuno, y la mención del propio escritor como uno de los personajes unidos a la guerra, lo que puede estar relacionado con la sonada película acerca de la vida y muerte de Unamuno durante la guerra, lo que refuerza la idea del poder que tienen los medios en la conformación del imaginario sobre hechos históricos y la llamada memoria mediática (Martínez Rodríguez, 2014), y, en este caso, la utilización del cine para el conocimiento de este hecho histórico (Ibars y López, 2006; López Serrano, 2019). En ambos casos, este hecho no debería desligarse de haberlos trabajado como autores relevantes de la Generación del 27 en la asignatura de Lengua Castellana y Literatura durante la secundaria, lo que ofrecería un marco interpretativo al visionado de la ficción mediática. 
Unido a la idea de mediatización de la historia debemos destacar la previamente mencionada influencia de los medios de comunicación en la composición del imaginario colectivo. La mención de personajes como Carrero Blanco o Juan Carlos I, relacionados con la guerra civil, puede ser muestra de los vínculos que se han creado en torno a las acciones de la banda terrorista ETA, el fin del franquismo y la posterior instauración de la monarquía. Todos ellos han sido hitos de los que se ha servido el discurso oficializado para la formulación de creencias y la unión de causas y consecuencias en el desarrollo de la historia reciente de España. Muchos de ellos, además, han sido llevados al cine o a docuseries emitidas en televisión, por lo que pueden ser personajes y hechos conocidos por los participantes.

En cuanto a las actitudes que pueden trabajarse en el aula, pese al alto porcentaje de respuestas recogidas en la categoría NS/NC (27,9\%), podemos observar cómo los participantes sí intuyen o conocen la finalidad y usos que el tratamiento de la guerra civil puede tener en el aula, aunque los datos muestren unas frecuencias no demasiado destacables. Las actitudes relacionadas con la competencia ciudadana tienen cierta predominancia sobre el resto de categorías, lo que coincide con la importancia del tratamiento de los valores cívicos en el aula de primaria (Ortiz et al., 2015) y la idoneidad de trabajar temas conflictivos para el desarrollo de esta competencia (López-Facal y Santidrián, 2011). Además, mencionan actitudes de interés por conocer la historia y relacionarla con la comprensión del presente, reforzando la idea del tratamiento de temas conflictivos en el aula para no repetir errores del pasado (Domínguez-Almansa y López-Facal, 2016).

Con unos resultados similares, la propuesta de trabajar la empatía también es destacable, pues es una de las claves del pensamiento histórico (Molina y Salmerón, 2020). Del mismo modo, también las emociones y los sentimientos ocupan un lugar destacado en la tipología de actitudes a trabajar en el aula, reforzando la idea propuesta por Estepa y Martín (2018) de la necesidad de establecer vínculos emocionales con las víctimas, para no olvidarlas. Aunque los datos sean residuales, cabe destacar la mención a la posibilidad de trabajar actitudes de conciencia, de reflexión y de relación del pasado con nuestro presente (Morgade, 2017), lo que es, sin duda, uno de los elementos claves al trabajar la historia con memoria.

Por último, hay que destacar las respuestas que no han sido actitudes sino conceptos generales, lo que muestra el desconocimiento de una parte del alumnado sobre las competencias actitudinales con relación a las ciencias sociales; además otros alumnos han respondido utilizando actividades concretas de aula, frente a la propuesta de tipos de actitudes que pueden trabajarse. Por lo tanto, observamos la necesidad de profundizar en estos aspectos en los programas de formación inicial del profesorado. 


\section{CONCLUSIONES}

Este estudio realizado en el País Vasco sobre el conocimiento que tiene el profesorado en formación sobre la guerra civil española y su posible aplicación en el aula de primaria ha permitido constatar el alto grado de desconocimiento sobre la temática, reforzando la idea de Arias et al. (2019) de la escasa alfabetización del alumnado hispano que finaliza la secundaria. Todo apunta a que la enseñanza de la historia desde un enfoque lineal y basado en sucesos bélicos y políticos perdura en las etapas obligatorias de educación, en el que no hay espacio para la reflexión y el debate (Bel y Colomer, 2017), debido en cierta medida a la necesidad de memorizar (Ibagón y Miralles, 2019) de cara a aprobar el examen de acceso a la universidad. Ello supone un recuerdo de personajes y acontecimientos, ligados sobre todo a la historia de batallas y cambios de gobierno, donde los mandatarios, militares, políticos y dictadores predominan sobre otros personajes del ámbito social.

Ante ello, se concluye la necesidad de realizar cambios en la enseñanza de la historia, integrando una perspectiva más social y alejada de la narración de hechos militares. Existe, sin lugar a dudas, una necesidad de dar protagonismo a los grupos invisibilizados (Acosta y Quintero, 2008; Díez, 2013), como los de las mujeres u otras minorías (Anguita Ortega, 2018) y a las víctimas de la represión franquista (Izquierdo, 2018), que pueden trabajarse mediante la recuperación de historias y sucesos asociados a éstos gracias a los testimonios, sin duda una de las fuentes más destacables en este proceso.

Además de los contenidos, la formación del futuro profesorado presenta importantes lagunas en torno a la posible aplicación de temas conflictivos en el aula, y la oportunidad de trabajar la competencia ciudadana (Molina et al., 2013). Ello implica, además, el desconocimiento de las actitudes que el tratamiento de temas conflictivos como la guerra civil pueden llevar implícitos. Es decir, no conocen el "para qué», ni el "cómo», y ello sugiere la conveniencia de apostar por un cambio también en los grados de educación y, sobre todo, en las materias de ciencias sociales en las que se trabaje la memoria histórica y los temas conflictivos. Además, en pocas ocasiones se toma en consideración la «memoria mediática» (Martínez Rodríguez, 2014) que es generadora de conocimientos y opinión en ese mismo alumnado, por lo que debería plantearse cuál es el origen de estos conocimientos y cómo pueden utilizarse para acercar la historia al alumnado de los grados de educación.

Trabajar la memoria de la guerra civil en España, donde apenas se hace -o no se hace bien-, es una cuestión de compromiso democrático (Delgado-Algarra, 2019). Tal y como ya apunta Izquierdo (2018), aún no se han asumido las interpretaciones alternativas sobre la guerra en España, al contrario que otros países que han sufrido sucesos similares. Por ello, y en vista de los resultados, es necesaria la construcción de un relato didáctico que integre también la perspectiva de quienes perdieron la guerra y sufrieron la represión, como vía para la reparación de las víctimas, 
y formar una ciudadanía más crítica. Debe ser una prioridad formar a futuros docentes que aprendan a trabajar una "historia problematizada» (Sánchez-Agustí, et al., 2019) desde la contramemoria crítica (Cuesta, 2007). Mostrar la importancia del tratamiento de la guerra civil en el aula de primaria, ofrecer las herramientas y recursos necesarios para ello, y que, en consecuencia, el futuro alumnado sea capaz de desarrollar actitudes de ciudanía, empatía y reflexión crítica que les ayude a conocer el pasado, comprender el presente y cambiar así el futuro.

\section{REFERENCIAS BIBLIOGRÁFICAS}

Anguita Ortega, A. (2008). La presencia de la Guerra Civil Española en el currículo educativo del Bachillerato andaluz. IJNE: International Journal of New Education, 2, pp. 77-94.

Acosta, G. y Quintero, V. (2008). Memoria, cultura y patrimonio. En G. Acosta., A. Del Río y J. M. Valcuende (coords.), La recuperación de la memoria histórica: una perspectiva transversal desde las ciencias sociales (pp. 124-136). Fundación Centro de Estudios Andaluces.

Arias, L., Egea, A., Sánchez, R., Domínguez, J., García F. J. y Miralles P. (2019). ¿Historia olvidada o historia no enseñada? El alumnado de Secundaria español y su conocimiento sobre la Guerra Civil. Revista Complutense de Educación, 30(2), pp. 461-478. https://doi.org/10.5209/RCED.57625

Aróstegui, J. (2004). La historia vivida: sobre la historia del presente. Alianza.

ArrietaUrtizberea.I. (2016). Recordaryolvidar:emprendedores ylugares de memoria. En I. Arrieta Urtizberea, (ed.), Lugares de memoria traumática: representaciones museográficas de conflictos políticos y armados (pp. 11-22). Universidad del País Vasco / Euskal Herriko Unibertsitatea, Argitalpen Zerbitzua = Servicio Editorial.

Bel, J. C. y Colomer, J. C. (2017). Guerra Civil y franquismo en los libros de texto actuales de Educación Primaria: análisis de contenido y orientación didáctica en el marco de la LOMCE. Cabás: Revista del Centro de Recursos, Interpretación y Estudios en materia educativ, 17, pp. 1-17.

Cáceres, P. (2003). Análisis cualitativo de contenido: Una alternative metodológica alcanzable. Psicoperspectivas, 2(1), pp. 53-82. 
Castrillo, J., Gillate, I., Luna, U. e Ibáñez-Etxeberria, A. (2021). Developing social and civic competence via apps: the role of historical memory in the initial teacher training. En C. J. Gómez Carrasco, P. Miralles Martínez y R. López Facal (eds.), Handbook of research on teacher education in history and geography (pp. 367389). Peter Lang.

Cuesta, R. (2007). La enseñanza de la historia como contramemoria crítica. En S. Leoné Puncel y F. Mendiola Gonzalo (coords). Voces e imágenes en la historia: fuentes orales y visuales: investigación histórica y renovación pedagógica: Actas del Congreso Internacional de Historia "Fuentes Orales y Visuales», IruñeaPamplona, septiembre, 2005. Universidad Pública de Navarra.

Cuesta, R. (2014). Genealogía y cambio conceptual. Educación, historia y memoria. Archivos analíticos de políticas educativas, 22(1). https://doi.org/10.14507/ epaa.v22n23.2014

Cunningham, M. (1999). Saying sorry: The politics of apology. Political Quarterly, 70(3), pp. 285-285. https://doi.org/10.1111/1467-923X.00231

Delgado-Algarra, E. J. (2019). Compromiso democrático, patrimonio y memoria en la enseñanza de la historia. Revista PH Instituto del Patrimonio Histórico, 96, pp. 222-224. https://doi.org/10.33349/2019.96.4303

Delgado-Algarra E. J. y Estepa, J. (2014). El Patrimonio como huella de la memoria histórica: análisis didáctico de dos monumentos en España y Japón. Clio. History and History teaching, 40, pp. 1-10.

Delgado-Algarra E. J. y Estepa Giménez, J. (2016). Ciudadanía y memora histórica en la enseñanza de la historia: análisis de la metodología didáctica en un estudio de caso en ESO. Revista de investigación educativa, 32(2), pp. 521-534. https:// doi.org/10.6018/rie.34.2.224891

Díez, E. J. (2013). La memoria histórica en los libros de texto escolares. Didáctica de las Ciencias Experimentales y Sociales, 27, pp. 23-41. https://doi.org/10.7203/ dces. 27.2373

Domínguez-Almansa, A. y López-Facal, R. (2016). Memoria histórica, patrimonio y formación del profesorado de educación primaria. En S. Molina, N. Lloch y T. Martínez (eds.), Identidad, ciudadanía y patrimonio. Educación histórica para el siglo XXI (pp. 71-86). Trea. 
Domínguez-Almansa, A. y López-Facal, R. (2017). Formación de maestros y educación patrimonial. Estudios pedagógicos, 43(4), pp. 49-68. https://doi.org/10.4067/ S0718-07052017000400003

Duarte Piña, O. (2018). La enseñanza de la Historia en el bachillerato y su devenir innovador. Investigación en la Escuela, 96, pp. 67-79. https://doi.org/10.12795/ IE.2018.i96.05

Fernández Muñoz, B., Criado, A., Lechuga, S., Osuna, J. L. y de los Reyes, J. L. (2018). Saber Historia, formar ciudadanos o aprobar la selectividad: una investigación sobre la enseñanza de la historia reciente de España en 2.ㅇ de Bachillerato. En D. Verdú, C. Guerrero y J. L. Villa (coord.), Pensamiento histórico y competencias sociales y cívicas en Ciencias Sociales (pp. 123-134). Ediciones de la Universidad de Murcia.

Figlio, K. (2017). Remembering as reparation: Psychoanalysis and historical memory (Studies in the psychosocial). Palgrave Macmillan.

Eiroa, M. (2020). Memoria e historia en redes sociales: nuevos soportes de resistencia al olvido de la Guerra Civil española y el Franquismo. Historia y memoria, 21, pp. 71-108. https://doi.org/10.19053/20275137.n21.2020.9659

Estepa, J. y Martín, M. (2018). Competencia en conciencia y expresiones culturales y educación histórica. Patrimonios en conflicto y pensamiento crítico. En C. J. Gómez Carrasco y P. Miralles (coords.), La educación histórica ante el reto de las competencias. Métodos, recursos y enfoques de enseñanza (pp. 75-86). Octaedro.

Estepa, J. y Delgado-Algarra, E. J. (2021). Educación ciudadana, patrimonio y memoria en la enseñanza de la historia: estudio de caso e investigación-acción en la formación inicial del profesorado de secundaria. REIDICS. Revista de Investigación En Didáctica de Las Ciencias Sociales, 8, pp. 172-189. https://doi. org/10.17398/2531-0968.08.172

Flick, U. (2015). El diseño de investigación cualitativa. Editorial Morata.

Gálvez, S. (2006). El proceso de la recuperación de la 'memoria histórica' en España: Una aproximación a los movimientos sociales por la memoria. International Journal of Iberian Studies, 19(1), pp. 25-51. https://doi.org/10.1386/ ijis.19.1.25/1 
Gillate, I., Ibáñez-Etxeberria, A., Molero, B. y Vicent, N. (2016). Visibilizando la historia de las mujeres a través del patrimonio en contextos informales: el Museo de la Minería del País Vasco. En S. Molina, N. Llonch, y T. Martínez. (eds.), Identidad, ciudadanía y patrimonio. Educación histórica para el siglo XXI (pp. 167-186). Trea.

Gillate, I., Luna, U., Castrillo, J. e Ibáñez-Etxeberria, A. (2020). Historical Memory in Heritage Education Apps: A Resource for Building Social and Civic Competence. En E. J. Delgado-Algarra y J. M. Cuenca-López (Coords.), Handbook of Resarch of Citizenship and Heritage Education (pp. 285-310). IGI-Global. https://doi. org/10.4018/978-1-7998-1978-3.ch014

González, M. P. y Pagés, J. (2014). Historia, memoria y enseñanza de la historia: conceptos, debates y perspectivas europeas y latinoamericanas. Historia y Memoria, 9, pp. 275-311. https://doi.org/10.19053/20275137.2941

Gutiérrez, J. L. (2007). La Memoria de la Historia reciente española. El reconocimiento de un viaje de la esperanza a la derrota. En G. Acosta, A. del Río y J. M. Valcuende (coords.), La recuperación de la memoria histórica. Una perspectiva desde las Ciencias Sociales (pp. 33-44). Centro de Estudios Andaluces/Junta de Andalucía.

Halbwachs, M. (1995). Memoria histórica y memoria colectiva. REIS: Revista Española de Investigaciones Sociológicas, 69, pp. 209-222. https://doi. org/10.2307/40183784

Hernández-Cardona, X. y Rojo, M. (2012). Arqueología y didàctica del conflicto: el caso de la guerra civil española. Revista de Didácticas Específicas, 6, pp. 159176.

Herrero Acosta, X y Ayán Vila, X. M. (2016). De las trincheras al museo: sobre el reciente proceso de patrimonialización de la Guerra Civil española en Euskadi. En I. Arrieta Urtizberea (ed.), Lugares de memoria traumática: representaciones museográficas de conflictos políticos y armados (pp. 99-122). Universidad del País Vasco / Euskal Herriko Unibertsitatea, Argitalpen Zerbitzua = Servicio Editorial.

Ibagón, N. J. y Miralles, P. (2019). Historia a enseñar, historia enseñada e historia aprendida. Posibilidades investigativas en el campo de la Educación Histórica en Iberoamérica. Historia y espacio, 15(53), pp. 9-18. https://doi.org/10.25100/ hye.v15i53.8777 
Ibars, R. y López, I. (2006). Historia y cine. Clío: History and History Teaching, 32.Izquierdo Martín, J. (2018). Recuerdo sobre fondo gris. Democracia y memoria herida en España. Confluenze, 10(2), pp. 105-126. https://doi. org/10.6092/issn.2036-0967/8884

Jelin, E. y Lorenz, F. G. (2004). Educación y memoria. La escuela elabora el pasado. Siglo XXI.

Ley Orgánica 52/2007, de 26 de diciembre, por la que se reconocen y amplían derechos y se establecen medidas en favor de quienes padecieron persecución o violencia durante la guerra civil y la dictadura. (2006). Boletín Oficial del Estado, 310, de 27 de diciembre de 2007, https://www.boe.es/buscar/pdf/2007/BOEA-2007-22296-consolidado.pdf

Llorente, A., Gillate, I, Ibáñez-Etxeberria, A. y Vicent, N. (2012). Patrimonio industrial y programas intergeneracionales: el caso del Museum Cementos Rezola. En O. Fontal, P. Ballesteros y M. Domingo (coords.), I Congreso Internacional de Educación Patrimonial: Estado de la cuestión y perspectivas de futuro. Comunicaciones (pp. 229-237). IPCE-OEPE.

López-Facal, R. y Santidrián, V. M. (2011). Los "conflictos sociales candentes» en el aula. Iber: Didáctica de las ciencias sociales, geografía e historia, 69, pp. 8-20.

López Noguero, F. (2002). El análisis de contenido como método de investigación. XXI Revista de Educación, 4, pp. 167-179.

López Serrano, M. J. (2019). El cine como propuesta pedagógica en el alumnado del Grado de Maestro en Educación Primaria. El Futuro del Pasado, 10, pp. 327341. https://doi.org/10.14516/fdp.2019.010.001.012

Maestro, P. (2002). El modelo de las historias generales y la enseñanza de la historia. Didáctica de las ciencias experimentales y sociales, 16, pp. 3-33.

Martínez Rodríguez, R. (2014). Profesores entre la historia y la memoria. Un estudio sobre la enseñanza de la transición dictadura-democracia en España. Enseñanza de las Ciencias Sociales, 13, pp. 41-48. https://doi.org/10.1344/ ECCSS2014.13.4

Molina, S., Miralles, P. y Ortuño, J. (2013). Concepciones de los futuros maestros de Educación Primaria sobre formación cívica y ciudadana. Educatio siglo XXI: Revista de la Facultad de Educación, 31(1), pp. 105-126. 
Molina, S. y Salmerón, A. (2020). La empatía como elemento para la adquisición del pensamiento histórico en alumnos de bachillerato. Un estudio de caso centrado en la Guerra Civil española y el franquismo. Panta Rei: revista de ciencia y didáctica de la historia 14(1), pp. 129-153. https://doi.org/10.6018/ pantarei.444761

Morgade, I. (2017). «Tras las huellas del maestro»: Una propuesta didáctica para el tratamiento de la represión de la memoria en el aula. Didáctica de las ciencias experimentales y sociales, 32(1), pp. 3-23. https://doi.org/10.7203/ dces.32.8207

Nets-Zehngut, R. (2013). Palestinians and Israelis collaborate in addressing the historical narratives of their conflict. Quest: Issues in Contemporary Jewish History, 5, pp. 232-252.

Olick, J. F. \& Robbins, J. (1998). Social memory studies: From «Collective Memory» to the Historical Sociology of Mnemonic Practices. Annual Review of Sociology, 24, pp. 105-140. https://doi.org/10.1146/annurev.soc.24.1.105

Ortiz, E., Izquierdo, T. y Miralles, P. (2015). Los valores cívicos en los textos del Grado de Educación Primaria. Contextos educativos. Revista de Educación, 18, pp. 6178. https://doi.org/10.18172/con.num18

Payà, A. (2013). Spaanse kinderen. Los niños españoles exiliados en Bélgica durante la guerra civil. Experiencia pedagógica e historias de vida. El Futuro del Pasado, 4, pp. 191-205. https://doi.org/10.14201/fdp.24753

Pagès, J. (2019). Ciudadanía global y enseñanza de las Ciencias Sociales: retos y posibilidadespara elfuturo. REIDICS, 5, pp.5-22.https://doi.org/10.17398/25310968.05.5

Roigé, X. (2016). De monumentos de piedra a patrimonio inmaterial: estrategias políticas, museológicas y museográficas de presentación de la memoria. En I. Arrieta Urtizberea (ed.), Lugares de memoria traumática: representaciones museográficas de conflictos políticos y armados (pp. 23-48). Universidad del País Vasco / Euskal Herriko Unibertsitatea, Argitalpen Zerbitzua = Servicio Editorial.

Rojo, M. C., Cardona G., Romero, M., Feliu, M., Jiménez, L., Íñiguez, D. y HernándezCardona, F. X. (2014). Patrimonio, conflicto y relevancia histórica. Una 
experiencia formando a los futuros profesionales de la educación. Clío. History and teaching, 40.

Saíz, J. y Fuster, C. (2014). Memorizar historia sin aprender pensamiento histórico: las PAU de Historia de España. Investigación en la escuela, 84, pp. 47-58.

Sánchez-Agustí, M., Martínez-Rodríguez, R., Miguel-Revilla, D. y López-Torres, E. (2019). Ideas de los jóvenes españoles acerca del pasado reciente: el caso de la Transición a la democracia. El Futuro del Pasado, 10, pp. 215-255. https://doi. org/10.14516/fdp.2019.010.001.008

Sánchez-Lafuente, J. (2008). ¿Qué tratamiento se da a la II República, a la Guerra Civil y al Franquismo en los libros de texto de historia de 40 de ESO? En G. Acosta, A. Del Río y J. M. a Valcuende (coords.), La recuperación de la memoria histórica: una perspectiva transversal desde las ciencias sociales (pp. 195-202). Centro de Estudios Andaluces.

Sonlleva Velasco, M. y Sanz Simón, C. (2019). "Vivir la infancia en tiempos de guerra». Un proyecto de innovación con fuentes orales en el ámbito universitario. El Futuro del Pasado, 10, pp. 393-436. https://doi.org/10.14516/ fdp.2019.010.001.015

Tint, B. (2010). History, Memory, and Intractable Conflict. Conflict Resolution Quarterly, 27(3), pp. 239-256. https://doi.org/10.1002/crq.258

Valls, R. (2007). La Guerra Civil española y la dictadura franquista: las dificultades del tratamiento escolar de un tema potencialmente conflictivo. Enseñanza de las ciencias sociales: revista de investigación, 6, pp. 61-74. 
